\title{
Index des noms de lieux
}

Académie de Vienne 57, 61, 65, 75, 83, 249

Adamovce (château d') 166

Aix-la-Chapelle (paix d') 123, 178

Albertina (musée de l') $89,97,111$

Allemagne 25, 28, 32, 152, 264-265, 307, 309, 339-340, 377

Ambras (château d') 256

Antol ou Anton (musée, château d') 165

Anvers 61

Aragon 5

Arolsen 181, 184, 309

Augsbourg 72, 83, 181, 371, 377

Augustusburg 181

Autriche antérieure 12, 107, 151-153, 194

Bad Saulgau 153

Baden 152, 236, 311

Bade-Wurtemberg 153

Balassagyarmat 115,170

Bamberg 182, 265, 377

Banat 149, 174-175, 248

Banská Štiavnica (Schemnitz en allemand) 113, 117, 165, 189, 192, 194, 232-233

Banská Bystrica (Neusohl en allemand) 189

Basse-Autriche 102, 104, 107, 153, 188, 190, 221-222, 225-227, 235-237, 245-246, 265, 277, 309, 311, 342, 344, 373, 384, 395

Bavière $1,10,18,27,91,153,155,157$, 181-184, 226, 231-232, 330, 338, 340, $353,367,389,396$

Belgique $32,97,175,177$

Belvédère 259, 399

Bernolákovo (château de) 166, 231

Bešenovo (monastère de) 175

Bohême (royaume de) 4, 7, 10-11, 12, 14-15, $18,22,30,84,88,99,101,105$, 107-108, 139-140, 148, 153-158, 160-162, 179, 186-187, 189, 197-198, 207, 211, 220, 226-228, 231, 238, 242-243, 256, 261, 264, 303-305, 308-309, 322-323, 326, 328-329, 336,
339, 341-342, 345, 348-357, 359-360, 364-365, 367-368, 370, 376-381, 385, $390,394,396,418,424,430,433$

Bojnice (musée et château de) 112, 165-166, $238,339,342,346,409$

Bologne 51

Bolzano (Bozen en allemand) 100, 152, 243 , $245,335,339,354$

Brabant (duché de) 120, 176, 214, 241, 268, 401, 404

Breslau 107, 263

Břevnov (abbaye de) 84, 158, 187, 220, 227, $265,353,390-391$

Brno (Brünn en allemand) 107, 160

Bruchsal (château de) 181, 266, 314, 371, 377

Bruck (château de) 277

Bruges 44, 61-62, 95, 118, 123-124, 127-128, 130, 176-177, 203, 239, 241-242, 360-361

Brühl (château de) 181, 183, 217, 340

Brukenthal (musée) 279-280, 337, 371

Bruxelles 32, 61-62, 80, 118-120, 122-123, $128,130,177,235,239-241,267-268$, 302, 361, 402-403, 405-406

Buda (Budapest, Ofen) 32-33, 84, 91, 115, $164,170,188,191,193,228-230,238$, 255-256, 260, 267, 275, 337, 339, 346, 385,418

Burgenland 139, 164, 275-276, 309

Carinthie 101, 151, 153, 245

Carniole (duché de) 151, 153-154, 326

Castello Sforzesco (château des Sforza) 126, 179

Cekínov Grad (Leopoldsruhe en allemand) 326

Celje 105, 154, 307

Červený Kameň (musée et château de) 33, 165-166, 234, 314-315, 348, 422

Český Krumlov 159

Číčov (château de) 166, 315

Cologne 76, 183-184, 211, 396

Corvey (abbaye et château de) 181, 265 
Croatie 11, 32, 164, 187

Csekleszar (château de) ou Bernolákovo 231

Csorna (abbaye des Prémontrés de) 168

Eckartsau (château d') 352

Eggenberg (château) 154, 214, 372-373

Eisenstadt 275, 277, 307, 309

Enns 152

Esterháza (palais d') 263-264, 276, 346

Esztergom 109, 115, 193

Feldsberg (château de) 90

Fertőd (palais de) 113, 161, 238, 264, 346

Flandre (comté de) 120, 123, 145, 176, 214, 240,361

Florence $56,60,71,88-89,97,126$, 177-178, 245, 394, 403

France $6,10,20,56,58-59,85,93,127,172$, 179, 211-212, 239, 247, 297, 304, 329, $363,384,390,411$

Francfort-sur-le-Main 183, 226, 242, 262, 377

Franconie 180

Fribourg-en-Brisgau 106-107, 130, 153, 191, 194-195, 249

Gand 118, 123, 176-177, 203, 214, 239, 241-242, 360-361

Gênes 71

Genève 302

Gödöllő (château de) 161, 228-230, 261, 263, 272, 337, 339, 342, 346, 395

Gorizia 126-127, 151, 246-247, 335

Göttweig (abbaye de) 187, 219-221, 371, 377

Grande-Bretagne (Angleterre) 5, 10, 73, 211, 400

Graz 114, 152, 154, 214, 235, 262, 373

Gripsholm (château de) 97

Győr 168, 346

Hajós (château de) 170

Haute-Autriche 1, 151, 153, 187, 190, 205 , 221, 265, 389

Haute-Hongrie 116, 150, 164, 170-172, 189, 194, 315, 412, 422

Heilbronn 181

Hlohovec (château de) 166
Hofburg (Vienne et Innsbruck) 87, 113, 258, 339, 345, 385, 394, 413, 417

Holič (château de) 166, 190

Hongrie 4, 7, 10-11, 12, 15, 18, 22, 29-30, 32-33, 59, 83-84, 98-99, 101, 103, 105, 107-109, 111-113, 115-116, 118-119, 125, 127, 139-140, 148-150, 155-157, 161-165, 167-168, 170-175, 179, 184, 186-187, 189, 192-193, 197-198, 202, 211, 228-234, 237-238, 242, 261, 263-264, 275-276, 291, 303, 305, 307-309, 315, 319, 322, 324, 326, 328-342, 345-346, 348-350, 352, 354, 356-357, 359-360, 362, 364-365, 367, 370-371, 373, 376-377, 379-381, 385, 394-396, 412, 416-418, 424, 430, 433-434

Hopovo (monastère de) 175

Hradčany (Hradschin) 376, 413

Hradisko (couvent prémontré de) 228

Innsbruck 87, 93, 104, 113, 153-154, 188, 191, 195, 202, 214, 235, 243, 245 , 255-260, 262, 339, 345, 385, 394, 410-411, 413, 417

Italie $32,56,60,71,73,85,88,97,108$, 126-127, 177-178, 196, 243

Kalocsa 169, 327

Karlobag (monastère de) 187

Karlowitz 161, 174-175, 268

Keszthely 161, 272

Kežmarok (château et musée de) 116, 118, 172, 397, 412, 422

Klagenfurt 98, 101, 152, 235, 245, 262

Klosterneuburg (abbaye de) 187, 222, 359

Komárno (ou Komáron) 113, 130, 170, 238

Konopiště (château) 158, 394

Košice 173, 194, 412

Kremnica (Kremnitz en allemand) 165, 189

Krems 102, 152, 309-310, 339-340

Kroměříž (Kremsier en allemand) 107, 160, 220

Krušedol (monastère de) 175

Kunsthistorisches Museum (Musée des Beaux-Arts, Vienne) 33, 84, 88, 90, 298, 345, 379, 417-418 
Lambach 103, 227

Levoča 173,412

Lier 97, 122, 177, 242

Lilienfeld (abbaye de) 107, 187, 204, 219 , 224-225, 373

Linz 152-153, 205, 227, 235, 262

Litoměřice (Leitmeritz en allemand) 158-159, 198

Litomyšl 158-159, 341

Ljubljana (Laibach en allemand) 105, 154, 326, 328

Lombardie 127, 178-179, 396

Lunéville 276

Luxembourg 32, 119, 176-177, 245, 405

Madrid 403

Mantoue 91-92, 126, 177-178, 191, 196, 249

Melk (abbaye de) 98-99, 103-104, 153, 187, 205, 218-219, 221, 225-227, 265, $326-327,373,384$

Milan $60,64,71,82,88,126,128,177,179$, 196, 202

Mirbach (palais) 33

Mohács (bataille de) 156, 276

Moravie 11, 107, 148, 158, 160, 187, 197-198, 220, 227-228, 231, 373, 396

Musée du Louvre 297

Musée lorrain de Nancy 120, 122, 402, 404-405

Namur 177

Nancy 120, 122, 402, 404

Nelahozeves (château de) 158

Neuwaldegg (château de) 399

Newby Hall (château de) 211

Nová Baňa (Königsberg en allemand) 189

Novi Sad 273

Nuremberg 181-182, 363-365, 367, 371, $375,377-379,430$

Offices (Galerie des) 97, 403

Olomouc (Olmütz en allemand) 109 , 157-158, 160-161, 198, 217, 220, 228, $339,368,373$

Olténie 174

Opočno 158-159, 377
Osseg 158

Ostende 119, 123, 177, 239

Palais Pitti (Florence) 97

Pannonhalma (abbaye de) 167-168, 187, 371, 377

Pardubice 159

Paris 56-59, 61, 71, 297, 405

Parme 61, 89, 178-179

Passarowitz (paix de) 174

Passau 184, 266

Pavie 92, 196

Pays-Bas autrichiens 12, 45, 60-61, 75, 97 , 118-119, 122, 126-127, 175, 179, 181, $189,198,239-240,242,360,401,403$, 405-406, 412, 434

Pest 115

Pfullendorf 153

Pitti (palais) 394

Prague $32-33,84,88,155-158,160$, 187-188, 202, 205, 207, 220, 226-228, 231-232, 236, 255-257, 260, 262, 264-265, 319, 335, 342-344, 353-354, 367-369, 376, 385, 390-391, 409, 413

Presbourg (Bratislava, Pozsony, Pressburg) 32-33, 42, 81-83, 88, 93, 107, 110-115, 130, 162, 165, 168, 170-171, 188, 192, 194, 202, 228, 230, 235, 237-238, 255-256, 259, 262, 274 , 276, 280, 291, 330, 334, 337-342, 344, $351,354,376,389,401,412,416$

Prusse $10,41,144,180-182,330$

Ptuj 154, 423

Rastatt (paix de) 175, 178

Rein (abbaye de) 215

République tchèque 32-33, 101, 309, 339, 394

Rhénanie 180

Rohrau (château de) 277

Rome 46, 56, 60-61, 64, 71, 85-86, 88-92, 140

Roumanie 164, 279, 337

Rychnov 158-159

Saint-Pétersbourg 71, 92

Salzbourg 91, 103, 139, 152 
Sankt Blasien (abbaye de) 153

Sankt Florian (abbaye de) 83, 104, 187, 204-205, 219-221, 227, 265, 267, 363, $367,372,416$

Sankt Pölten 152, 339, 409

Šaštín-Stráže (Schlossberg) 190

Saxe 10, 27, 71, 81, 120, 158-159, 182, 233, 256

Schlägl (couvent prémontré de) 187

Schönbrunn (château de) 72, 75-76, 86, $188,215,223,259,312,361,392,394$, $399,417,420-421$

Schwäbisch Hall 181

Seehof (château de) 181-182, 265, 377

Seitenstetten (abbaye de) 102-103, 187, 369, 384, 391

Serbie 32, 174

Sibiu (Hermannstadt en allemand) 279-280, 371

Silésie 10-11, 107, 155, 160, 177, 231, 241, 323, 350, 401

Slovaquie 29, 32-33, 101, 105, 112, 164-166, $170,173,189,232,276,315,342,348$, 412, 422

Slovénie 32, 105, 423

Smolenice (château de) 166, 314

Sopron 238

Spire (Speyer en allemand) 181, 266, 314 , 371, 377

Sremski Karlovci 175

Steyregg 227

Stockholm 74

Strahov (abbaye de) 158, 160, 187

Styrie 105, 151, 154, 190, 215, 423

Suède $5,71,97,400$
Svatý Kopeček (chapelle du) 228

Syrmie 273

Tallós 192, 202, 231, 276

Tatras 117, 171

Temesvár 174-175, 248

Teplá (monastère) 158, 160, 187, 377

Toscane 90,126, 178, 256, 396

Transylvanie 164, 174, 279, 371

Trautson (Palais) 76, 85, 218

Trieste 126, 177

Turin 71

Tyrnau (Trnava, Nagyszombat) 93, 170, 191, 193, 338

Tyrol 12, 104, 151-152, 243, 339, 359

Uhrovec (château de) 112

Vác 228, 230, 263

Valtice (château de) 107, 158, 187, 396

Veltrusy (château de) 157-158, 231, 261, 264, 377

Venise $61,71,107,212$

Versailles 5, 138, 394

Vizovice (château de) 158, 309, 339

Vorarlberg 152

Vršac 175

Wiener Neustadt 152

Znojmo 107, 187, 220

Znojmo, Louka u Znojma (Klosterbruck en allemand, couvent) 107, 187, 220

Zsira (château de) 167 